\title{
For the record: What kind of health plan does a senator have anyway?
}

$\mathrm{E}$ mbattled Senator Mike Duffy has expressed concerns about losing his health and benefits package if he is suspended or ousted from the upper chamber. Here's what he had to say during his Oct. 28 address to his Senate colleagues:

"Not only is it a firing without a firing, as Senator Segal has correctly pointed out, it deprives me not only of a paycheque but of a health plan, of life insurance. This, a guy who came back off sick leave because of serious heart problems. Who is going to buy the heart drugs I need? What kind of a country do we have when the power can override the sick-leave provisions of the federal Government of Canada health care act or arrangement?"

"I've got a certificate at home that says I'm a member of the government health plan. Well, guess what? Senator Carignan has the power to tear it up. Doesn't matter. I gave up a life insurance plan because I had government insurance under the Senate. What? That's all going to be gone in the twinkling of an eye because of a conspiracy?"

In addition to the basic health coverage that all Canadians receive through their provincial health care plans, senators are deemed executive members of the federal public service. As such, they are in the executive members' category of the Public Service Health Care Plan. On top of their \$135200 salaries, all senators, including Duffy, are entitled to the following health and insurance benefits:

- Hospital benefits of up to $\$ 220$ per day (roughly the cost of a private room)

- Catastrophic drug coverage $(100 \%$ of drug costs are covered once a member has already spent $\$ 3000$ in a year in out-of-pocket costs, including copayments plus annual deductible of $\$ 60$ per person, $\$ 100$ per family)

- Erectile dysfunction drugs (80\% of the $\$ 500$ maximum per year)

- Psychologists' services $(80 \%$ of the $\$ 1000$ maximum per year)

- Physiotherapists' services $(80 \%$ of the first $\$ 500$ per year, and another $80 \%$ of anything more than $\$ 1000$ per year)

- Eyewear, \$275 every two years

- Osteopath, naturopath, massage therapist, and podiatrist or chiropodists' services $(80 \%$ of a $\$ 300$ maximum per year)

- Chiropractor's services $(80 \%$ of the $\$ 500$ maximum per year)

- Speech language pathologist $(80 \%$ of the $\$ 500$ maximum per year)

- Nursing services $(80 \%$ of $\$ 15000$ per year maximum)

- Life insurance worth a minimum of twice the annual adjusted salary, or a base of $\$ 270000$, with the option to buy additional coverage

- Long-term disability benefits that amount to $70 \%$ of annual salary, for up to two years (with the possibility of continuation based on being unable to earn two-thirds of annual salary)

If a senator (or any other member of the health plan) goes on a leave without pay, he or she may be required to pay the full cost of their health coverage, depending upon the length and type of leave, according to the Treasury Board of Canada Secretariat's website. Currently, Duffy's employer - the federal government - pays the costs of his health plan, minus any copayments or deductions. — Laura Eggertson, CMAJ

CMAJ 2013. DOI:10.1503/cmaj.109-4650 